\title{
Fabrication and Morphology Evaluation of Poly-vinyl Alcohol-Chitosan Nanofibers Prepared by Electrospinning Direct Deposition
}

\author{
Pedro Hernández ${ }^{1}$, Rosalva Josefina Rodríguez-Córdova ${ }^{1}$, F.J. Martínez Vázquez ${ }^{3}$, Iván E. Moreno-Cortez ${ }^{3}$, \\ Aarón Martínez-Higuera ${ }^{1}$, Armando Lucero-Acuña ${ }^{2}$, Enrique Álvarez Ramos ${ }^{1}$, Reynaldo Esquivel ${ }^{1}$. \\ ${ }^{1 .}$ Department of Physics, University of Sonora, Hermosillo, Sonora, Mexico \\ 2. Department of Chemical and Metallurgical Engineering, University of Sonora, Hermosillo, Sonora, Mexico \\ ${ }^{3}$ Universidad Autónoma de Nuevo León, Fac. de Ingeniería Mecánica y Eléctrica, Av Universidad s/n Cd \\ Universitaria, Nuevo León México
}

Electrospinning direct deposition (EDD) has been extensively studied in biomedical and tissue engineering. EDD process involves viscous and volatile polymeric solution which is loaded in syringe. High voltage is applied through the needle and then the polymer is charged trigger nanofiber formation from the charged needle to the grounded target [1]. Electrospun polymeric nanofiber it is a wide variety of potential application owing to their outstanding properties as a good processability, chemical stability, flexibility and high biocompatibility. Mechanical properties and high biocompatibility allow developing bioinspired model as adherent material useful for cell culture for tissue regenerative engineering. Copious applications of polymeric nanofibers have been studied in recent scientific works [2],[3]. Polymeric Nanofibers (PNF) are an important candidate for biomedical developments. Chitosan is a semisynthetic polymer extracted from shrimp and crab shells. Physical properties of chitosan as high solubility, mucoadhesive and biocompatibility allow designing applications oriented to medicine and regenerative fields. In this research, Polyvinyl alcohol (PVA)-chitosan (CS) electrospun nanofibers with variations of morphology and diameters were produced by electrospinning direct deposition (EDD). Experimental: 10\% (w) PVA solution was prepared dissolving MPVA and HPVA with a 1:1 ratio. Furthermore, 3, 5 and 7\% LVC (low viscosity chitosan) solutions were prepared. The following mixture was then prepared: $\mathrm{VG}_{0}(10 \% \mathrm{PVA}), \mathrm{VG}_{1}(10 \% \mathrm{PVA}-3 \% \mathrm{LVC}$ at $4: 1$ ratio), $\mathrm{VG}_{2}\left(10 \% \mathrm{PVA}-5 \% \mathrm{LVC}\right.$ at $4: 1$ ratio), $\mathrm{VG}_{3}\left(10 \% \mathrm{PVA}-7 \% \mathrm{LVC}\right.$ at $4: 1$ ratio), $\mathrm{VG}_{4}(10 \% \mathrm{PVA}-3 \%$ $\mathrm{LVC}$ at $3: 1$ ratio), $\mathrm{VG}_{5}(10 \% \mathrm{PVA}-3 \% \mathrm{LVC}$ at $2: 1$ ratio). The electro-spinning conditions for all samples were as follows: $10 \times 10 \mathrm{~cm}$ aluminium substrates, with a distance Tip-collector gap of $10 \mathrm{~cm}$, a Feed-rate of $0.5 \mathrm{~mL} / \mathrm{hr}$ and a voltage of $15 \mathrm{kV}$. We present morphological characterization of the electrospun nanofibers analysed by Scanning Electronic Microscopy (SEM), figure 1. Sample $\mathrm{VG}_{1}$ with the lowest chitosan concentration (Figure 1a), shows the typical fiber structure obtained by electrospinning process, diameter was measured, and size average corresponds to 150-200 $\mathrm{nm}$. Increase of the Chitosan concentration promotes the production of more robust fibers. This result confirms the product obtained by X. Geng et al [4], they obtained diameters around 130-150 $\mathrm{nm}$. The glass transition $(\mathrm{Tg})$ and melting temperature $\left(\mathrm{T}_{\mathrm{m}}\right)$ of the samples (each weighing $5 \mathrm{mg}$ ) were examined with DSC2910 from TA Instruments (at IFSC-USP), from 50 to $250{ }^{\circ} \mathrm{C}$ at a heating rate of $10^{\circ} \mathrm{C} / \mathrm{min}$, in a nitrogen atmosphere and $50 \mathrm{~mL}$. $\mathrm{min}^{-1}$. As can be observed in table 1, there is a reduction in the areas of peaks of the $\mathrm{VG}_{1}$ and $\mathrm{VG}_{2}$ samples compared to the VG0 samples, although the Tm of the samples are practically unaffected, remaining around $220{ }^{\circ} \mathrm{C}$. On the other hand, figure 2 shows that the $\mathrm{Tg}$ of the samples undergoes a change due to chitosan, in $\mathrm{VG}_{2}$ the $\mathrm{Tg}$ decreases due to the addition of hydrophilic groups. In this study, PVA-Chitosan nanofibers were successfully prepared. An important change in Tg and morphology was obtained when the Chitosan concentration was modified. From the results obtained in this research, PVA-Chitosan nanofibers are potential candidates as bioinspired scaffold system for biomedical issues [5].

\section{References:}

[1] A.M.Abd El-aziz, AzzaEl-Maghraby, Nahla A.Tahaa, Arabian Journal of Chemistry, 10 (2017), p. 1052.

[2] N.AkhmalNgadiman et al, Procedia Manufacturing 2 (2015), p. 568. 
[3] F. Barzegar et al, Journal of Physics and Chemistry of Solids 77 (2015), p. 139.

[4] X. Geng, O. Hyeong Kwon, J. Jang, Biomaterials 26 (2005), p. 5427.

[5] The authors acknowledge funding from Consejo Nacional de Ciencia y Tecnologìa (CONACyT) project number 255791-INFR-2015, Catedra CONACYT 2264 and PDCPN 2014-247326.
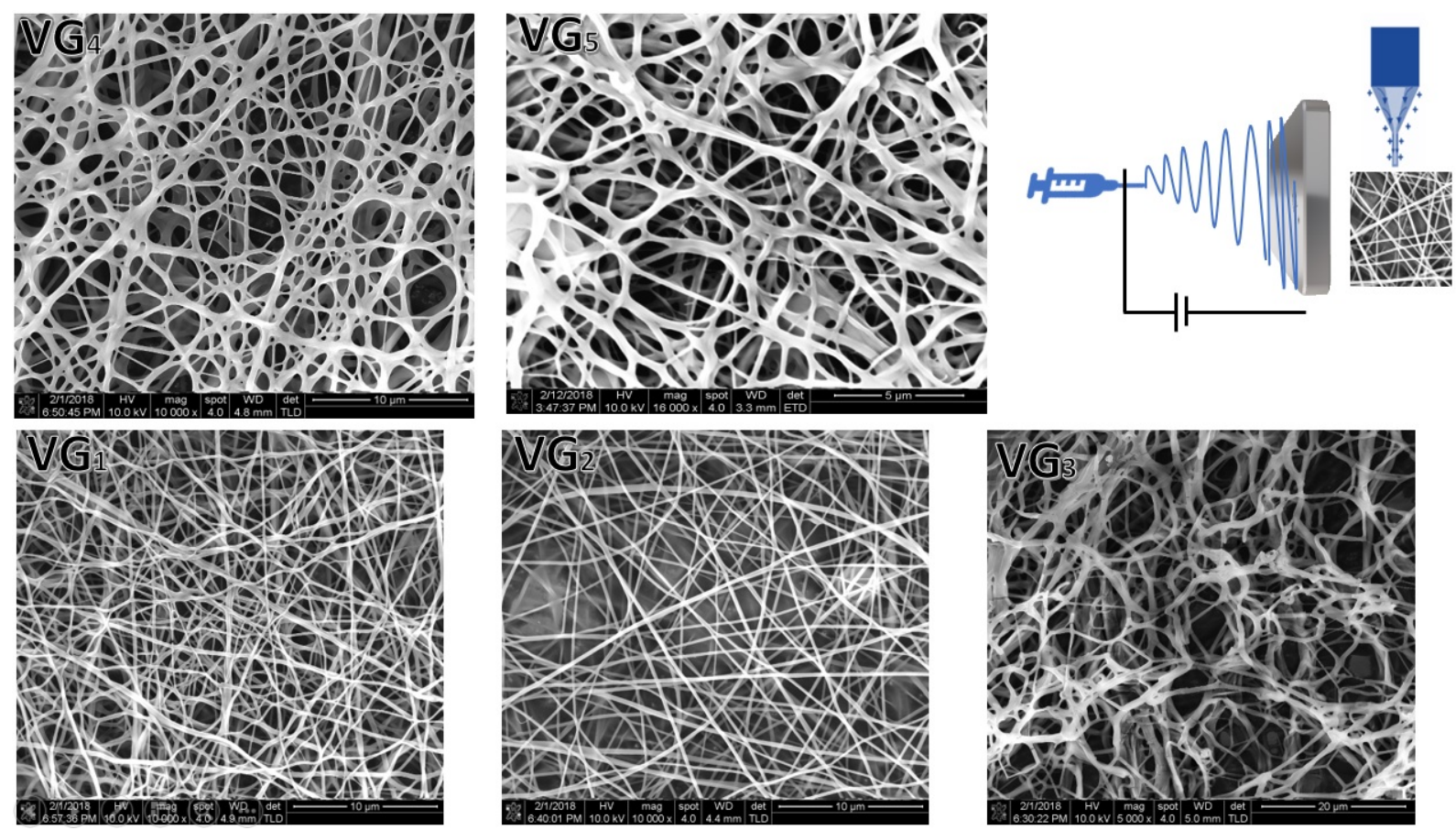

Figure 1. Scanning Electron Microscopy for samples $\mathrm{VG}_{1}, \mathrm{VG}_{2}, \mathrm{VG}_{3}, \mathrm{VG}_{4}$ and $\mathrm{VG}_{5}$.

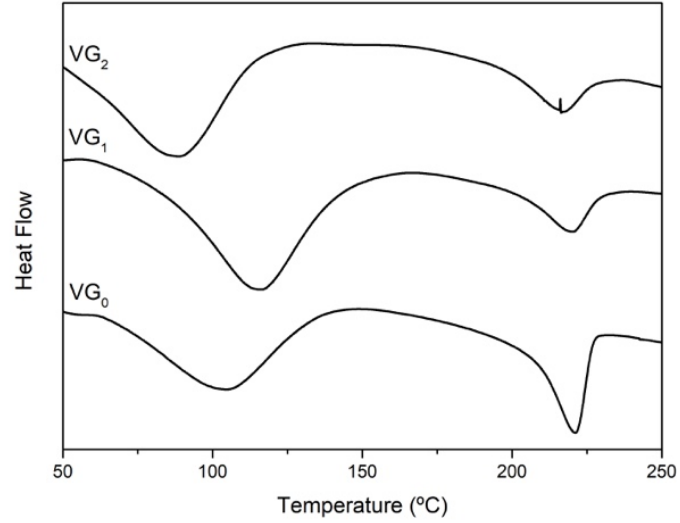

Figure 2. DSC curves for samples $\mathrm{VG}_{0}, \mathrm{VG}_{1}$, and $\mathrm{VG}_{2}$.

Table 1. Glass transition (Tg) and melting temperature (Tm) of $\mathrm{VG}_{0}, \mathrm{VG}_{1}$, and $\mathrm{VG}_{2}$.

\begin{tabular}{|l|l|l|l|l|}
\hline Sample & $\mathrm{Tg}\left({ }^{\circ} \mathrm{C}\right)$ & $\mathrm{Tg}-\Delta \mathrm{H}(\mathrm{J} / \mathrm{g})$ & $\mathrm{T}_{\mathrm{m}}\left({ }^{\circ} \mathrm{C}\right)$ & $\mathrm{T}_{\mathrm{m}}-\Delta \mathrm{H}(\mathrm{J} / \mathrm{g})$ \\
\hline $\mathrm{VG}_{0}$ & 104.91 & 119.0 & 221.24 & 49.58 \\
\hline $\mathrm{VG}_{1}$ & 115.77 & 189.5 & 220.25 & 26.70 \\
\hline $\mathrm{VG}_{2}$ & 87.94 & 1950 & 216.36 & 31.15 \\
\hline
\end{tabular}

